\title{
Recurrent Leukemia
}

National Cancer Institute

\section{Source}

National Cancer Institute. Recurrent Leukemia. NCI Thesaurus. Code C148425.

The reemergence of leukemia after a period of remission. 